\title{
Building a Collection of Iranian Music at the University of Toronto Music Library
}

\author{
by Houman Behzadi
}

\section{Abstract}

This paper describes the process of building a collection of Iranian music at the University of Toronto Music Library. The initiative was a response to the noticeable interest in Iranian studies, and more specifically Iranian music, at the University of Toronto. Following an environmental scan, the author elaborates on the observations that identified the need for this project. The rationale for building the collection was further formed through a field trip to Iran, which provided an overview of the country's print publication and audiovisual production output. A number of opportunities and challenges encountered in acquiring music materials from this country are discussed and the methods used in the selection and acquisition processes explained. Subsequent to an account of the project's outcomes, the author outlines the current limitations of the collection and discusses areas for its further development and discoverability.

Keywords: diversity, music collections, music libraries, Canada, Iran, Persian, area studies, ethnomusicology, Iranian studies, collection development, selection, acquisition, vendors

Paper type: Case study

\section{Introduction}

Music is as diverse as the people and communities engaged in its creation and practice. In Canada, a country that encourages the formation of a cultural mosaic, the coexistence of many musical traditions has redefined people's engagement with global music. This, along with the internationalization of Canadian academic institutions, has diversified music scholarship in the higher education sphere. This diversification necessitates an array of library resources to support new areas of teaching and research. Collections in particular play a fundamental role in forming libraries' responses to the heterogeneous needs of music library users.

Houman Behzadi (houman.behzadi@utoronto.ca) is the Music Collection Development Librarian at the University of Toronto, in Toronto, Canada.

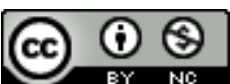

This work is licensed under a Creative Commons Attribution-NonCommercial 4.0 International License. 
As its title states, this article is a case study describing the process and outcomes of building a collection of Iranian music at the University of Toronto ( $U$ of T) Music Library. Utilizing an evidence-based approach, this initiative aimed to enhance the diversity of the Music Library's collection by acquiring textual and audiovisual materials from Iran, an underrepresented region in North American academic library music collections. By evidence-based, I am referring to information that leads to an understanding of internal and external circumstances pertinent to the scholarship of the library's main constituents; information that supports the addition of a new branch to the evolving tree of resources at the library. By enhancing diversity, in this context I am alluding to the collecting of library resources that fall outside the mainstream areas of curation of North American academic libraries. These include, among others, resources that have traditionally been overlooked, or that can only be obtained from regions that pose specific challenges for academic library selectors. The former could be addressed and overcome by employing benchmarking techniques, participating in existing collection building programs, or by collaborating with vendors who have expertise in building subject specific or area studies collections. The latter, depending on the subject area, could demand a set of skills including a combination of subject and language expertise. Additionally, familiarity with the acquisition region's publishing scene and socio-political atmosphere could be essential. ${ }^{1}$

\section{Environmental scan}

My OCLC WorldCat queries for major Iranian music publishers revealed that a portion of Iranian music materials, textual and audiovisual, are being collected in North America. Libraries are likely collecting these through broader acquisition plans (for example, the Library of Congress (LC) Cooperative Acquisition Program (CAP $)^{2}$ ), donations, or established library vendors such as Iran Farhang. ${ }^{3}$ To date, however, I have found little evidence of targeted collection building initiatives. ${ }^{4} \mathrm{My}$ searches on the Library and Information Science Abstracts (LISA) database, Google Scholar, and Google yielded reference to only one other initiative for building an Iranian music collection in North America. The website of the Center for Iranian Music (CFIM) at Carnegie Mellon University lists "establishing an extensive library of Iranian music within the University library system" ${ }^{5}$ as one of CFIM's educational initiatives. Upon contacting the Music Librarian at the Carnegie Mellon University Libraries, I learned that they currently hold a relatively small collection (14 books and $84 \mathrm{CDs}$ ) of Iranian music materials. Their collection grows in response to the specific needs of the CFIM faculty and students. ${ }^{6}$

1. There exists a panoply of textual and audiovisual materials in a multitude of languages about the music of Iran. This article and the project it describes are concerned only with materials published or produced in Iran.

2. "Cooperative Acquisitions Program (CAP): Islamabad, Pakistan (Library of Congress Overseas Offices)," Library of Congress, last updated June 28, 2016, accessed November 26, 2016, https://www.loc.gov/acq/ovop/islamabad/islamabad-coop.html.

3. "Iran Farhang," Iran Farhang, accessed December 16, 2016, http://www.iranfarhang.com/ShowCases.aspx?ShowCase=4.

4. Harvard Library has a substantial collection of Iranian ML and MT class books (their public catalogue shows 319 titles), followed by Princeton University Library, whose collection in this area is similar in size to that of the University of Toronto Libraries.

5. "About," Center for Iranian Music, accessed November 20, 2016, http://centerforiranianmusic.org/about.

6. The Carnegie Mellon University Libraries' Iranian music collection can be viewed via http://search.library.cmu.edu/vufind/Search/Reserves?inst=38891\&course=2907\&dept=MUSRESV. 
The following environmental scan is divided into three distinct but closely related sections, all of which are pertinent to this article's main theme. These are: 1) Area studies collections in general: regardless of the geographic region(s) in question, area studies collection building follows similar patterns and faces a series of kindred obstacles; 2) Diversity in collections: a "collection response" to our changing user demographics is highly relevant to the overall mission of higher education institutions in North America; and 3) Iranian studies in particular: the heightened importance of Iranian studies in North America has played a significant role in the formation of library collections of Iranian materials in a variety of subjects and disciplines.

\section{Area studies collections}

While the topic has been treated in scholarly journals for several decades, there remains room for further research and examination of the current state of area studies collections in academic institutions. ${ }^{7}$ A simple keyword search ("area studies" collections) in LISA generated twenty-seven peerreviewed results, some covering the process of building collections from specific regions, some capturing the overall trends in building area studies collections, and others that look into collaborative collection building ventures. ${ }^{8}$ Regardless of any specific focus, the literature confirmed the integral role of the library in supporting area studies scholarship at academic institutions. In imagining a utopia for the work of area studies practitioners (librarians included), Hazen and Spohrer advocate for "an area studies program that is growing both in size and in significance, that sustains visible ties to the target culture, and that enjoys continuing deep institutional support." ${ }^{\prime}$ The authors accentuate the place of the library, and in particular its role in building area studies collections, by stating that "the institution must support the full range of library activities relevant to the field, particularly providing for processing as well as acquisitions." 10

Over the last two decades, librarians have repeatedly voiced concerns that support for the acquisition of foreign language and area studies materials has not corresponded with the pace of internationalization of academic institutions. In 1999, Case and Jakubs stated that support for international resources in the US had been "severely eroded."11 Their analysis of the global publishing market identified the increased volume of publishing output, the rising prices of serials (in particular science and technology journals), and dramatic currency fluctuations as significant budgetary pressure points, all of which had negatively affected the acquisition of international resources. ${ }^{12}$ Furthermore, the low circulation numbers of foreign language materials have made these resources a target for alleviating the pressure on

7. This is especially true for Canadian academic libraries. Little has yet been written about how academic libraries in this country plan to respond to the multi-faceted needs of our diverse user groups in light of libraries' decreased purchasing power, which has mainly resulted from the Canadian dollar's devaluation in 2015.

8. A similar search on the Library, Information Science \& Technology Abstracts (LISTA) yielded nineteen results from academic journals, encompassing a similar scope to what was found in LISA.

9. Dan C. Hazen and James H. Spohrer, Building Area Studies Collections (Wiesbaden: Otto Harrassowitz Verlag, 2007), 4.

10. Ibid.

11. Mary Case and Deborah Jakubs, "Building the Global Collection: World Class Collection Development, a Chronicle of the AAU/ARL Global Resources Program," Journal of Library Administration 28, no. 1 (1999): 64.

12. Ibid, 66-67. 
acquisition budgets. ${ }^{13}$ In 2000, the Task Force on the Acquisition and Distribution of Foreign Language and Area Studies Materials released a report articulating its vision and providing strategies to overcome the challenges of building global collections in North American libraries. The Task Force-initiated by the Association of American Universities (AAU) in collaboration with the Association of Research Libraries $(A R L)$ - provided a set of recommendations for North American research universities and libraries. These included the organization of a distributed program, including shared responsibility for the acquisition, organization, and description of foreign language materials; the implementation of clearly defined collection building programs by major universities; ${ }^{14}$ and the incorporation of a user-centred approach that would attract the support of faculty members. ${ }^{15}$ These recommendations eventually led to the creation of the Global Resources Program, which currently functions under the umbrella of the Center for Research Libraries (CRL) and comprises fourteen distinct projects, including the Middle Eastern Materials Project (MEMP). MEMP's focus is the preservation of "collections in digital and microform format of unique, rare, hard to obtain, and often expensive research material for Middle East studies." 16

The increasing demand for area studies resources, and the availability of information sharing technologies, have made inter-institutional collecting models very attractive. ${ }^{17}$ It has been argued that although these collaborative initiatives seem increasingly logical-especially in the current financial climate-they pose their own challenges. Their very nature necessitates a significant investment in communication and collaboration between the participating institutions. Their success is also dependent on the sustainability of financial and human resources, which can be difficult to foresee during the implementation stage. ${ }^{18}$ The challenges reported in the late 1990 s and early 2000 s seem to persist, even if slightly different in nature. In 2013, the report of the International \& Area Studies Collections in 21st Century Libraries conference listed several common concerns of the conference participants. Included were financial constraints-and in particular the reduction of governmental and institutional funding; recruitment and retention of area studies selectors; and difficulties in developing collaborative models catering to the needs of all participating members. ${ }^{19}$

The Library of Congress (LC) Cooperative Acquisition Programs (CAP) has made a significant contribution to North American libraries' area studies collections. The program uses LC's six overseas offices to collect, provide access to, and disseminate library materials from regions where the use of traditional

13. Case and Jakubs, "Building the Global Collection," 68.

14. Initially, three distinct projects were proposed with the ultimate goal of acquiring materials from Latin America, Germany, and Japan.

15. Association of American Universities (AAU) Research Libraries Project: Reports of the AAU Task Forces, "Acquisition and Distribution of Foreign Language and Area Studies Materials," Journal of Library Administration 29, no. 3/4 (2000): 57-58.

16. “MEMP," Center for Research Libraries, accessed November 20, 2016, https://www.crl.edu/programs/memp.

17. Hazen and Spohrer, Building Area Studies Collections, 5.

18. Case and Jakubs, "Building the Global Collection," 76.

19. Steve Witt, "International \& Area Studies Collections in 21st Century Libraries: Report of a Conference," International Leads 27, no. 1 (2013): 7, http://www.ala.org/irrt/sites/ala.org.irrt/files/content/intlleads/leadsarchive/201303.pdf. 
acquisition methods proves inadequate. ${ }^{20}$ The Islamabad office is responsible for three Middle Eastern countries, namely Pakistan, Afghanistan, and Iran. It acquires and catalogues monographs, serials, newspapers, and audiovisual materials for the LC and many other American and Canadian libraries. In 2014, the field directors of the Islamabad and New Delhi offices expressed concerns about maintaining the level of expected service. The main reason provided was uncertainty in federal funding, and its impact on employee hiring, training, and retention in the two offices. It was also reported that new travel curfews in Pakistan had caused difficulties for the Islamabad office. ${ }^{21}$ A survey studying the collection practices of South Asian specialists proved a heavy reliance on the LC programs, which no doubt speaks to their success. Common criticisms of the programs seem to be the homogeneity of different collections, inability to place firm orders, ${ }^{22}$ and the absence of non-print media (audiovisual, special, and antiquarian items, etc.). ${ }^{23}$

\section{Diversity in collections}

The rationale behind the premeditated diversification of academic library collections can be easily conceptualized. If collections are an integral part of the modern library's suite of services, and if library services are indeed designed with the end user in mind, then the need to diversify the collections according to user needs is fully apparent. Gulati opines that "the strength of libraries has always been the diversity of their collections and commitment to serving all people ... because [libraries] provide a forum for diverse ideas and points of view that can help us learn about and better understand ourselves and each other." ${ }^{24}$ Selectors in large and complex academic libraries are ideally positioned to define diversity according to local realities. They also can assess their collections' diversity using a variety of quantitative and qualitative tools. ${ }^{25}$ Ciszek and Young's article on diversity collection assessment in large institutions provides a useful list of such assessment strategies. For quantitative methods the authors refer to collection-centred tools such as WorldCat Collection Analysis (benchmarking against other institutions); comparison with standard bibliographies; and the assignment of diversity codes. ${ }^{26}$ Qualitative methods include focus groups, patron interviews and surveys, and the employment of diversity subject specialists. ${ }^{27}$ In discussing the latter, the authors suggest the creation of a new role in

20. "Overseas Offices," Library of Congress, accessed November 21, 2016, https://www.loc.gov/acq/ovop/.

21. Mara Thacker, "Beyond the Library of Congress: Collecting Practices of South Asia Area Specialist Librarians," Library Resources \& Technical Services 59, no. 2 (2015): 79, https://journals.ala.org/index.php/Irts/article/view/5680/7050.

22. The programs function as approval plans with projected annual fees and less-than-desirable control of the selection process.

23. Thacker, "Beyond the Library of Congress," 75-6.

24. Anjali Gulati, "Diversity in Librarianship: The United States Perspective," IFLA Journal 36, no. 4 (2010): 289, http://www.ifla.org/files/assets/hq/publications/ifla-journal/ifla-journal-36-4 2010.pdf.

25. Matthew P. Ciszek and Courtney L. Young, "Diversity Collection Assessment in Large Academic Libraries," Collection Building 29, no. 4 (2010): 154-56.

26. The suggested method requires the assignment of specific agreed-upon codes to diversity items (e.g. AS for Asian American) at the selection and/or cataloguing stages. These codes would then allow for the creation of reports that capture different aspects (circulation, subject areas, etc.) of the titles acquired in a given area.

27. Ciszek and Young, "Diversity Collection Assessment," 156. 
libraries, a diversity specialist who collaborates with selectors in all areas to build or enhance diversity in their respective collections. ${ }^{28}$

Leong's 2013 study of ethnic diversity at the University of Toronto Libraries (UTL) presents a broad overview of the UTL's collections' diversity. He reports that the collection includes materials in more than 300 languages, necessitating the engagement of staff members with knowledge of one or more of these languages. His interviews with the UTL managers reveal their interest in "having an ethnically diverse team, serving the needs of the collection and the clientele whenever there is any new hiring opportunity. Yet, the availability of qualified candidates remains to be their primary concern." ${ }^{29}$ Leong's article is one of many that depict, directly or indirectly, a correlation between the diversity of library staff members and that of its collections. Some advocate for an active and aggressive collection of underrepresented resources, and warn against a heavy reliance on circulation statistics or demanddriven acquisition models in arriving at conclusions or long-term decisions. ${ }^{30}$ In academic libraries, a more diverse staff "can be invaluable in building diverse collections and creating services that best meet the needs of local and global communities." ${ }^{31}$ Looking at the common features of diverse collections would further elucidate the qualities required in a team of library personnel. Carter and Whittaker mention a high level of expertise in a subject/area, language concerns, focused collection development, and targeted international user communities as the common features of these collections, all of which necessitate the mediation of staff members with a combination of subject and language expertise. ${ }^{32}$

\section{Iranian studies}

Two elements in the twentieth century deeply influenced the state of Iranian studies in North America. First was the post-WWII economic and socio-intellectual atmosphere of the continent, which instigated the transfer of knowledge from Europe and other parts of the world to North America. Second, and more significant, was Iran's 1979 revolution-as well as the breakout of the Iran-Iraq war in the following year-which brought the massive and ongoing emigration of Iranians, and the formation of Iranian diasporas around the world. ${ }^{33}$ The settlement of numerous Iranian academics, journalists, literati, artists, and musicians in North America has resulted in the creation of dozens of centres, foundations, and initiatives related to Iranian studies in the US and Canada. A Wikipedia page devoted

28. Ciszek and Young, "Diversity Collection Assessment," 158.

29. Jack Hang-tat Leong, "Ethnic Diversity at the University of Toronto Libraries," Conference paper, IFLA World Library and Information Congress, Singapore (2013): 7, accessed November 20, 2016, http://library.ifla.org/67/1/101-leong-en.pdf.

30. Myrna Morales, Em Claire Knowles, and Chris Bourg, "Diversity, Social Justice, and the Future of Libraries," Portal: Libraries and the Academy 14, no. 3 (2014): 446.

31. Ibid, 441.

32. Lisa R. Carter and Beth M. Whittaker, "Area Studies and Special Collections: Shared Challenges, Shared Strength," Portal: Libraries and the Academy 15, no. 2 (2015): p.360.

33. Umberto Cicchetti, "Iranian Studies at Concordia University: A Unique Program in Canada," Islamic Perspective, no. 3 (2010): 109, accessed November 20, 2016, http://iranianstudies.org/wpcontent/uploads/2010/04/Islamic-perspective-Journal-number-3-2010.pdf. 
to Iranian studies provides an incomplete, and yet telling, list of these initiatives. ${ }^{34}$ The Foundation for Iranian Studies, based in Maryland; the Centre for Iranian Studies at Columbia University (particularly important for its association with Dr. Ehsan Yarshater, the founder of Encyclopædia Iranica); ${ }^{35}$ and the Program of Iranian Studies at the University of California, Los Angeles, are among the most important organizations of their kind in the US. Two notable initiatives in Canada are the Centre for Iranian Studies at Concordia University and the Toronto Initiative for Iranian Studies at the $\mathrm{U}$ of $\mathrm{T}$.

The Concordia University program benefits from Montreal's large and active Iranian community. Cicchetti, in discussing Iranian studies at Concordia, points to an increasing interest in the subject area among "students of both Iranian and non-Iranian backgrounds". ${ }^{36}$ The author describes how the program "is also aimed at a broad and interdisciplinary understanding of Iranian civilization as one entity with different manifestations, from pre-Islamic times through to the modern period and in various aspects ranging from language and art to the social sciences." ${ }^{37}$ In her article "Iranian Studies at the University of Toronto," Rivanne Sandler has provided a fascinating account of the formation and growth of Iranian studies at this institution. In 1961, ten years after the establishment of the Institute of Islamic Studies at McGill University, the University of Toronto created its Department of Islamic Studies. Iranian studies were a major component of the department from its inception. Several distinct factors contributed to the growth of the department, and particularly to its branch of Iranian studies: 1) the interest of certain influential Iranian studies professors; 2) development of fine library collections that supported Middle Eastern and Iranian studies; and 3) the role of the Royal Ontario Museum and its important collections. ${ }^{38}$ As Sandler has written, "The Royal Ontario Museum has been from the very beginning, and continues to be, an integral component of Iranian studies at the $U$ of $T$. It is an important resource in its collection of miniatures, manuscripts, ceramics, and textiles from Persia and Central Asia." ${ }^{39}$

The settlement of the world's second largest Iranian immigrant population in southern Ontario has significantly increased the number of Iranian students at the University of Toronto. A higher number of students has translated into additional funding and faculty hires, and subsequently an increased Iranian studies course offering. ${ }^{40}$ The 1996 merger of the Departments of Islamic Studies and of Near Eastern Studies into the present Department of Near and Middle Eastern Civilizations (NMC), as well as the foundation of the Toronto Initiative for Iranian Studies, have further expanded the scope of scholarship in this area: "The initiative is committed to establishing links with the Iranian community, and fostering interest in Iranian studies outside the university." ${ }^{41}$ Today, the Department continues to thrive as it

34. "Iranian studies," Wikipedia, accessed December 13, 2016, https://en.wikipedia.org/w/index.php?title=Iranian studies\&oldid=754632284.

35. "Ehsan Yarshater," Center for Iranian Studies, Columbia University, accessed November 10, 2016, http://cfis.columbia.edu/staff/Ehsan\%20Yarshater.

36. Cicchetti, "Iranian Studies at Concordia University," 111.

37. Ibid.

38. Rivanne Sandler, "Iranian Studies at the University of Toronto," Iranian Studies 42, no. 4 (2009): 612.

39. Ibid, 615.

40. Ibid, 618.

41. Ibid, 619. 
strengthens its links with other departments and faculties of the $U$ of $T$, with the city's Iranian community, and with other Iranian studies organizations across the globe. An example of recent collaborations is the publication of Iran Nameh, the quarterly journal of the Foundation for Iranian Studies, at the U of T. From 2011 until 2016, the Journal was published under the editorship of NMC faculty member Mohamad Tavakoli-Targhi. ${ }^{42}$

\section{Canada, Toronto}

According to Statistics Canada's National Household Survey (NHS), 163,290 people of Iranian origin resided in Canada in $2011 .{ }^{43} \mathrm{~A}$ comparison with 2006 reveals an average annual population growth of $6.87 \%$ over a five-year period. ${ }^{44}$ Assuming that a similar growth rate has persisted since 2011 , the current population of Iranians in Canada could be in the vicinity of 220,000 or $0.6 \%$ of the entire Canadian population. Toronto and its surrounding municipalities (York, Richmond Hill, and Vaughan) are home to the second largest Iranian population outside of Iran. Notwithstanding neighbourhoods with high-density Iranian populations, Iranian Canadians are well-integrated into the fabric of the greater Toronto area. Persian is regularly heard spoken at malls, subway stations, workplaces, and academic institutions alike. Toronto celebrates Iranian culture through numerous events that bring Iranian Canadians together year-round, with two noteworthy examples being the Tirgan and Cinelran festivals. Tirgan, the largest festival of Iranian culture outside of Iran, is a biennial event featuring Iranian music, dance, literature, arts and crafts, and food at Toronto's Harbourfront. ${ }^{45}$ Cinelran, an annual festival of contemporary Iranian film, provides a unique opportunity for cross-cultural exchange in the city. ${ }^{46}$

\section{The University of Toronto Faculty of Music}

The $U$ of T Faculty of Music, in particular its Department of Ethnomusicology, has for many years fostered an environment of global research and performance. The Faculty's 2016 Strategic Academic Plan articulates its intention to achieve greater diversity by encouraging the enrollment of "international students and students from other musical cultural traditions." 47 The Department of Ethnomusicology trains "students in the intellectual history, theory, methodology and practice of ethnomusicology, and ...

42. "Iran Nameh," Foundation for Iranian Studies, accessed on December 2, 2016, http://fisiran.org/en/irannameh.

43. Statistics Canada, Statistics Canada Catalogue no. 99-004-XWE, "Canada (Code 01) (table), National Household Survey (NHS) Profile," released September 11, 2013, accessed December 5, 2016, http://www12.statcan.gc.ca/nhs-enm/2011/dp-pd/prof/index.cfm?Lang=E.

44. Statistics Canada, Ethnocultural Portrait of Canada, "Ethnic origins, 2006 counts, for Canada, provinces and territories - 20\% sample data," modified October 6, 2010, accessed December 5, 2016, https://www12.statcan.gc.ca/census-recensement/2006/dp-pd/hlt/97562/pages/page.cfm?Lang=E\&Geo=PR\&Code=01\&Data=Count\&Table=2\&StartRec=1\&Sort=3\&Display=All\&CSDFilt er $=5000$.

45. “Tirgan," Tirgan, accessed December 9, 2016, http://www.tirgan.ca.

46. "Cinelran Festival," Cinelran, accessed December 9, 2016, http://www.cineiran.ca/about/.

47. University of Toronto Faculty of Music, "Music Strategic Academic Plan 2016-2021," unpublished report (2016): 14. Additionally, on page eight of this document, a list of globalization/internationalization initiatives includes: "[The Faculty of Music will] expand our global perspective on music to better reflect twenty-first-century musical realities by further developing our world-music cultural programs and scholarly studies of musics worldwide, and by connecting with the multicultural communities in the GTA and internationally." 
offer[s] courses and ensembles in diverse musical traditions from around the world." ${ }^{48}$ Currently, the Faculty has two members of Iranian origin in its departments of Ethnomusicology and Music Education..$^{49}$ Additionally, it has attracted several Iranian graduate students in doctoral and master's degree levels, some of whom focus specifically on different aspects of Iranian music. An ethnomusicology PhD candidate of note is Iranian classical vocalist and musician Sepideh Raissadat. Raissadat was the first female vocalist to sing solo in a public performance in Tehran after the 1979 Islamic revolution. ${ }^{50}$ Each year, she gives numerous concerts and recitals in North America and Europe, and has released several recordings in collaboration with other Iranian and Canadian musicians.

Raissadat's performances at the Faculty of Music are often sold out, and attract a significant number of Iranian Canadians to the campus of the University. The study of Iranian music gathered momentum with the engagement of tombak virtuoso Pedram Khavarzamani as the Faculty of Music's 2015 World Music Artist in Residence. This appointment led to the creation of the Iranian Music Ensemble, a for-credit ensemble open to percussion players from all areas of the $U$ of $T$.

\section{Identifying the need}

Shortly after my engagement at the Faculty of Music, I joined the Resource Sharing and Collection Development (RSCD) Committee of the Music Library Association (MLA). At the Committee's annual meeting in Atlanta, the Chair of the Committee at the time emphasized the importance of building music collections from challenging regions. His advocacy was later reflected in a future goal of the Committee in its 2014 annual report. ${ }^{51}$ Committee members were called upon to produce collection building guides for these regions, a mandate that struck a chord with me due to my nascent knowledge of the interest in Iranian music at the Faculty of Music. My initial goal was fairly modest, and entailed production of a LibGuide surveying existing initiatives, identifying important vendors, and introducing useful selections tools to North American selectors. I soon learned, however, that the chosen path was unpaved. I did not find any realized targeted initiatives, could not identify established library vendors of Iranian materials with internal music expertise, and I discovered very few selection tools (websites, bibliographies, trade catalogues) that I could recommend to colleagues in North American libraries. The 2009 Survey of Music-Library Personnel Characteristics provides a plausible reason for this gap: none of the survey respondents indicated a basic or bibliographic knowledge of Persian. ${ }^{52}$ Other speculative

48. "Ethnomusicology," University of Toronto Faculty of Music, accessed December 10, 2016, http://individual.utoronto.ca/kippen/Ethnomusicology/aboutus.html.

49. Dr. Farzaneh Hemmasi assumed the position of Assistant Professor of Ethnomusicology in 2013; Dr. Nasim Niknafs began a position as Assistant Professor of Music Education in 2014.

50. In Iran, women are banned from singing solo in public performances. Likewise, no sound recording featuring the solo singing voice of a woman would receive permission for distribution and/or sale from the Ministry of Culture and Islamic Guidance. Women are allowed to sing solo for female-only audiences in private gatherings.

51. MLA Resource Sharing \& Collection Development (RSCD) Committee, "Annual Report," unpublished document (2014): 1. "[The RSCD] Committee Web site would list specialty vendors and other tips from experienced bibliographers (beyond just music librarians where appropriate) for acquiring music materials published or produced in Latin America, Africa, the Middle East, South Asia, and East Asia."

52. Susannah Cleveland and Mark A. Puente, "Survey of Music-Library Personnel Characteristics, 2009," Notes 67, no. 4 (2011): 690. 
reasons include the lack of English language bibliographies of music in Iran; the scarcity of bilingual websites of Iranian music score and audiovisual vendors; and ongoing acquisition difficulties caused by cold Iran-US relations.

\section{First trip: Fieldwork}

In the spring of 2014, I was presented with the possibility of doing a few days of fieldwork in Tehran. The ultimate goal was to gain awareness of Iran's music publishing and recording industry outputs and to gather information for the production of the aforementioned LibGuide. Enthusiastic about the potential outcomes of this work, a $\mathrm{U}$ of $\mathrm{T}$ faculty member introduced me to a professor of ethnomusicology at the University of Tehran. I met with this professor at the School of Performing Arts and Music of the University of Tehran and greatly benefitted from his knowledge of the city's important music publishers and vendors. Subsequent to this meeting I visited a total of seven music publishers and vendors, a list of whom can be found in Appendix A. These meetings proved valuable as I developed a general understanding of the type, readership level, and price range of materials available on Tehran's market. I also formed invaluable working relationships with a number of people possessing intimate knowledge of the field. An example would be my initial meeting with the Editor-in-Chief of the Mahoor Music Quarterly journal, from whom I learned much about previous research and work done by Iranian music scholars. Additionally, I managed to acquire and bring back to Canada several key reference titles. These included Simin Halali's Bibliography of Music in Iran (published in 2007), ${ }^{53}$ two important volumes of Iranian music history survey, ${ }^{54}$ a guide to Iranian music theory, ${ }^{55}$ and several recorded anthologies of vocal and instrumental music. This small collection proved to be a crucial component for what came next.

The trip to Iran helped me envision the possibility of building a collection of Iranian music for the $U$ of $T$ Music Library. Ultimately, the university's support for Iranian studies, evident interest in Iranian music at the Faculty of Music, the possibility of travelling to Iran without a visa (due to my dual Iranian-Canadian citizenship), and the combination of my language (Persian) and subject (music and librarianship) knowledge formed the rationale for curating a collection of print and audiovisual materials in this area. The following selection/acquisition criteria were subsequently put in place, in consultation with two of our faculty members, to define the scope of the project:

1) Format: Books, music scores, periodicals, CDs, and DVDs

2) Genre and scope: Classical/traditional, regional, and religious music of Iran; and music of neighbouring countries provided criteria 3 and 4 are respected

3) Language: Persian

53. Simin Halali, Kitabshinasi-i musiqi dar Iran: fihrist-i mawzui-i kitab'ha, maqalat-i nashriyat-i (1354-1383), payan'namah'ha va țarh'ha-yi pizhuhishi [Bibliography of Music in Iran: Topical Lists of Books, Articles (1975-2004), Dissertations and Theses] (Tihran: Mu'assasah-yi Farhangi-Hunari-i Mahur, 2007).

54. Sasan Sipanta, Chashm'andaz-i musiqi-i Iran [An Overview of Iran's Music] ([Tihran?]: Mu'assasah-i Intisharat-i Mash'al, 1990); Ruhullah Khaliqi, Sarguzasht-i musiqi-i Iran [History of Iran's music] (Tihran: Mu'sisah-'i Farhangi-Hunari-i Mahur, [2011 or 2012]).

55. Muhammad Riža Fayaz, Shinakht-i dastgah'hai-i musiqi-i Irani [Understanding the Modes of Iranian Music] (Tihran: Mu'sisah-'i Farhangi-Hunari-i Mahur, 2012). 
4) Place of publication: Iran

5) Legal/ethical issues: Items approved by Iran's Ministry of Culture and Islamic Guidance and sold legally by authorized publishers or vendors

Although I had some familiarity with the identified genres, I needed to better acquaint myself with Iranian classical music history, theory, and practice in order to select judiciously and to hold meaningful conversations with the target publishers and vendors. The small collection I had brought from Iran proved sufficient for this purpose. The next step was to produce a proposal for the project (including a budget) for submission to the UTL administration. For the budget component of the proposal it was necessary to determine a feasible acquisition volume. In 2014, the UTL collection included a total of ninety-two Persian language ML and MT class books, with publication dates ranging from 1955 to $2011 .^{56}$ Forty-two of these titles had been acquired since 2008, when the Library began its collaboration with the Islamabad office of the Library of Congress. Halali's bibliography was used to identify the important missing titles published prior to 2007. To evaluate coverage of our LC CAP acquisitions of Iranian music, I relied on existing records in OCLC WorldCat and my own findings in Tehran. These investigations revealed that we had missed a significant number of titles suitable for inclusion in the UTL collection. Following calculation of the necessary acquisition budget, a proposal for one-time funding was submitted to the UTL administration and subsequently approved. ${ }^{57}$

\section{Legal/Logistical issues}

While the idea of a buying trip was very attractive, I was apprehensive about the logistics of shipping the materials to Canada in light of the stringent trade and business sanctions imposed on Iran..$^{58}$ On June 7, 2013, the Canada Border Services Agency (CBSA) released a number of amendments to the Special Economic Measures (Iran) Regulations, imposing a complete ban on imports and exports from and to Iran. The amendments encompassed a number of exemptions, including the importation of "informational materials." ${ }^{59}$ To verify our interpretation of this rather broad category, the UTL contacted Foreign Affairs and International Trade Canada for assistance. In response, a Federal Government Legal Officer confirmed the exemption of "books and other publications," but mentioned the possibility of the review/detention of goods by CBSA upon entry and recommended the inclusion of written statements of justification with the import documents. ${ }^{60}$ The suggested process seemed inefficient and lacked the

56. The Music Library's collection included only a handful of Iranian CDs, no DVDs, and no music scores.

57. I arrived at the estimated acquisition budget by assigning an average price of fifteen dollars to books and music scores and three dollars to audiovisual materials.

58. There has been a significant alleviation of sanctions and trade regulations with Iran since 2014. For up-todate information, visit: http://www.international.gc.ca/sanctions/countries-pays/iran.aspx?lang=eng.

59. Canada Border Services Agency, Customs Notice 13-013, "Amendments to the Special Economic Measures (Iran) Regulations," June 7, 2013, http://publications.gc.ca/collections/collection 2014/asfc-cbsa/Rv55-5-2013013-eng.pdf.

60. Foreign Affairs, Trade and Development Canada, email to the University of Toronto Libraries, January 23, 2015. "While we cannot provide a determination of whether or not a particular good is prohibited, if you determine that your import from Iran fits within one of the exemptions in the Iran SEMA Regulations, and you decide to import the good(s), you may want to set out in writing how the particular exemption applies and provide it to the CBSA with the other import documents, to assist them in making their determination." 
customs clearance guarantee we were hoping to receive. The only alternative for us was to seek the assistance of an established library vendor with legal methods of shipping or transshipping materials from Iran to Canada. For this we approached Iran Farhang, a vendor we had already been working with for several years. Iran Farhang graciously agreed to receive the materials purchased in Tehran, create order records for every item, and ship them to Canada.

\section{Second trip: Selection, acquisition, shipment}

The buying trip took place in January of 2015. I was able to obtain materials from each format and genre category listed in the previously mentioned selection and acquisition criteria. Selection was carried out on a title-by-title basis at local vendors' premises, and the materials were transported to Iran Farhang's head office at the end of each day. The collaboration with Iran Farhang was beneficial in a number of ways, in addition to their capacity to provide secure shipment of the collection to the UTL. For example: 1) they assisted with the reconciliation of all invoices; 2 ) they processed the materials, which gave them an overview of our desired readership level and performance quality; and 3) they created bibliographic records for every item in their database, which gives other institutions the opportunity to order a subset of the UTL collection (especially advantageous for the audiovisual titles unavailable outside of Iran).

The collection arrived at the UTL in February $2015 .{ }^{61}$ Table 1 provides an overview of the quantity and scope of the materials acquired.

Ninety-five of the ML and MT class titles in the acquired collection have publication dates equal to or greater than 2008, which shows that our collaboration with the LC CAP Islamabad Office had supplied only a representation of the "profile-fitting" publications in this area. It is important to note that a proactive selection of newly published titles from a vendor like Iran Farhang could result in unwanted overlap with the LC CAP approval plan because there is no way of identifying the LC plan's coverage until the materials arrive at the Library and are properly catalogued (a process that could take up to two years after publication of an item). So far, I have identified three duplications as a result of the buying trip to Tehran. Going forward, therefore, we expect to wait at least a year before firm ordering a title from Iran Farhang's new title announcement lists. ${ }^{62}$ As mentioned earlier, the LC CAP supplies no audiovisual materials and very few music scores (their 2016 shipment for the UTL included only one music score), so the buying trip was instrumental in building the collection in these categories.

61. Books were acquired from the Mahoor Institute and Part Publications. All music scores were selected from the Mahoor catalogue. The audiovisual materials were acquired from Mahoor and Barbad Music. Appendix A provides links to the online catalogues of these and other enterprises, offering an overview of the types of materials acquired during the buying trip.

62. My recent conversations with an Iran Farhang representative revealed that the company is one of the LC CAP suppliers. For institutions benefitting from the LC CAP, Iran Farhang's new title announcement lists could be used for retrospective gap-filling purposes. 


\begin{tabular}{|c|c|c|}
\hline Format & Quantity & Examples \\
\hline Books & 124 & $\begin{array}{l}\text { ML: general history surveys; study of religious music (tazieh) of Iran; } \\
\text { research on folk music from the Northern provinces of Gilan and } \\
\text { Mazandaran; history of music recording in Iran; song and singing of the } \\
\text { Kurdish people; nationalistic music of Iran; confluence of poetry and music } \\
\text { in Iran } \\
\text { MT: instrumental method books for tombak, baqlama (Turkish } \\
\text { instrument), and santur; dastgah (modal) music theory textbooks }\end{array}$ \\
\hline $\begin{array}{l}\text { Music } \\
\text { scores }\end{array}$ & 51 & $\begin{array}{l}\text { instrumental radifs by Ali Akbar Shahnazi; collection of short pieces from } \\
\text { Azerbaijan; compositions of Abolhasan Saba; anthologies of santur music }\end{array}$ \\
\hline CDs & 737 & $\begin{array}{l}\text { Sets: regional music of Iran (forty-eight CDs); music of the Bakhtiari } \\
\text { nomads (three CDs); collection of vocalist Gholamhosein Banan's } \\
\text { recordings (seventeen CDs) } \\
\text { Stand-alone titles: avaz and tasnif singing by artists such as Mohammad } \\
\text { Reza Shajarian, Salar Aqili, and Dariush Rafii; instrumental radifs and } \\
\text { improvisatory works; recitation of poetry from Ferdowsi and Hafiz (Persian } \\
\text { poetry is often used as the lyrics for improvisatory vocal works or avaz) }\end{array}$ \\
\hline DVDs & 25 & $\begin{array}{l}\text { concerts of prominent vocalists including Mohammad Reza Shajarian and } \\
\text { Mohammad Reza Lotfi }\end{array}$ \\
\hline Serial titles & 2 & $\begin{array}{l}\text { Mahoor Music Quarterly journal, volumes 1-7, 9, 10, 12-64; several } \\
\text { volumes of Avay-e-Sheida, a music magazine published by late tar virtuoso } \\
\text { Mohammad Reza Lotfi }\end{array}$ \\
\hline
\end{tabular}

\section{Limitations and further development}

The ban on all forms of public presentation of female solo singing in Iran (including commercial recordings) is manifestly translated into an underrepresentation of Iranian female vocalists in the UTL collection. Over the past two years, I have acquired a number of recordings produced outside of Iran to compensate for this gap, but more needs to be done to achieve better coverage. The collection might have been strengthened by the inclusion of items from small publishing houses, particularly those based outside of Tehran. In hindsight, I see that a buying trip coinciding with Tehran's annual International Book Fair could have been advantageous. Such a book fair would provide an opportunity to identify a larger number of vendors, publishers, and titles that could have been of interest to the UTL.

In regards to cataloguing and access, the majority of the books and music scores acquired were catalogued by the UTL Iranian bibliographer in the weeks following their arrival at the UTL. Cataloguing the audiovisual materials has been slower due to a shortage of staffing resources in this area. We have recently hired two graduate student library assistants with Persian language skills who are cataloguing this portion of the collection. Given the delay in providing access to these items, I foresee the need to 
further advertise the collection to our constituents using multiple approaches: 1) curation of an exhibition at the Music Library; 2 ) providing short introductions to the collection in classrooms or at the Faculty of Music's Iranian music events (i.e. Iranian Music Ensemble concerts); 3) informal and formal communications about the initiative at the $U$ of $T$ Department of Iranian Studies; and 4) looking for opportunities to engage with the members of the community at large to bring more awareness about the collection, attract important in-kind donations, and solicit feedback on enhancing the depth and breadth of the collection.

The collection will further develop through the UTL's established channels and according to the evolving needs of our faculty and students. Currently, I do not foresee a need for a future buying trip. For ML and MT class materials, the Library will rely primarily on the LC CAP. Retrospective gap filling will be done through benchmarking with other North American and European institutions, fulfilling purchase requests from our users, and the examination of Iran Farhang's new title announcement lists. I also receive email notifications of the Mahoor Institute's new releases (music scores and audiovisual materials) and will acquire titles that complement the existing collection. The Library's annual collection budget allows for these purchases. An appropriate future step would be a systematic assessment of the collection by looking into circulation numbers and by conducting interviews with the Iranian music collection's main users to learn about their use and evaluation of the collection.

\section{Conclusion}

Building a collection of Iranian music at the University of Toronto Music Library was a calculated and consultative endeavour in support of a somewhat new area of scholarship at the Faculty of Music. Using an environmental scan, the three categories of area studies, collection diversity, and Iranian studies were examined, revealing the confluence of external and internal factors that formed the rationale behind this collection building initiative. A combination of subject and language expertise, knowledge of the acquisition region and market, and the possibility of travelling to the region without a travel visa were essential in curating the collection. Consultations with $U$ of $T$ faculty members, a graduate student, librarians and support staff of the UTL Collection Development and Finance Departments, a faculty member at the University of Tehran, and many vendors and publisher representatives were instrumental in defining and achieving the project's objectives. Through this work, the links between the University of Toronto Libraries, an important library vendor, and several Iranian music publishers and producers were strengthened, which will facilitate future collection development processes for this and other academic institutions. 


\section{Bibliography}

Association of American Universities (AAU) Research Libraries Project: Reports of the AAU Task Forces. "Acquisition and Distribution of Foreign Language and Area Studies Materials." Journal of Library Administration 29, no. 3/4 (2000): 51-75.

Carter, Lisa R., and Beth M. Whittaker. "Area Studies and Special Collections: Shared Challenges, Shared Strength." Portal: Libraries and the Academy 15, no. 2 (2015): 353-73.

Case, M., and D. Jakubs. "Building the Global Collection: World Class Collection Development, a Chronicle of the AAU/ARL Global Resources Program." Journal of Library Administration 28, no. 1 (1999): 63-80.

Center for Iranian Music. "About." Accessed November 20, 2016. http://centerforiranianmusic.org/about.

Center for Iranian Studies. "Ehsan Yarshater." Center for Iranian Studies, Columbia University. Accessed November 10, 2016. http://cfis.columbia.edu/staff/Ehsan\%20Yarshater.

Center for Research Libraries. "MEMP [Middle East Materials Project]." Accessed November 20, 2016. https://www.crl.edu/programs/memp.

Cicchetti, Umberto. "Iranian Studies at Concordia University: A Unique Program in Canada." Islamic Perspective, no. 3 (2010): 108-115. Accessed November 20, 2016. http://iranianstudies.org/wpcontent/uploads/2010/04/Islamic-perspective-Journal-number-3-2010.pdf.

Cinelran. "Cinelran Festival." Accessed December 9, 2016. http://www.cineiran.ca/about/.

Ciszek, Matthew P., and Courtney L. Young. "Diversity Collection Assessment in Large Academic Libraries." Collection Building 29, no. 4 (2010): 154-61.

Cleveland, Susannah, and Mark A. Puente. "Survey of Music-Library Personnel Characteristics, 2009." Notes 67, no. 4 (2011): 686-715.

Fayaz, Muhammad Rizna. Shinakht-i dastgah'hai-i musiqi-i Irani [Understanding the Modes of Iranian Music]. Tihran: Mu'sisah-'i Farhangi-Hunari-i Mahur, 2012.

Foundation for Iranian Studies. "Iran Nameh." Accessed on December 2, 2016. http://fis-iran.org/en/irannameh.

Gulati, Anjali. "Diversity in Librarianship: The United States Perspective." IFLA Journal 36, no. 4 (December 2010): 288-93. http://www.ifla.org/files/assets/hq/publications/ifla-journal/ifla-journal36-4 2010.pdf.

Halali, Simin. Kitabshinasi-i musiqi dar Iran: fihrist-i mawzui-i kitab'ha, maqalat-i nashriyat-i (1354-1383), payan'namah'ha va țarh'ha-yi pizhuhishi [Bibliography of Music in Iran: Topical Lists of Books, Articles (1975-2004), Dissertations and Theses]. Tihran: Mu'assasah-yi Farhangi-Hunari-i Mahur, 2007.

Hazen, Dan C., and James H. Spohrer. Building Area Studies Collections. Beiträge zum Buch- und Bibliothekswesen 52. Wiesbaden: Otto Harrassowitz Verlag, 2007.

Iran Farhang. "Iran Farhang." Accessed December 16, 2016. http://www.iranfarhang.com/ShowCases.aspx?ShowCase=4.

"Iranian studies." Wikipedia. Accessed December 13, 2016. https://en.wikipedia.org/w/index.php?title=Iranian studies\&oldid=754632284. 
Khaliqi, Ruhullah. Sarguzasht-i musiqi-i Iran [History of Iran's music]. Tihran: Mu'sisah-'i Farhangi-Hunarii Mahur, [2011 or 2012].

Leong, Jack Hang-tat. "Ethnic Diversity at the University of Toronto Libraries." Conference paper, IFLA World Library and Information Congress, Singapore (2013). Accessed November 20, 2016. http://library.ifla.org/67/1/101-leong-en.pdf.

Library of Congress. "Cooperative Acquisitions Program (CAP): Islamabad, Pakistan (Library of Congress Overseas Offices)." Last updated June 28, 2016. Accessed November 26, 2016. https://www.loc.gov/acq/ovop/islamabad/islamabad-coop.html.

- - . "Overseas Offices." Accessed November 21, 2016. https://www.loc.gov/acq/ovop/.

MLA Resource Sharing \& Collection Development (RSCD) Committee. "Annual Report." Unpublished document (2014).

Morales, Myrna, Em Claire Knowles, and Chris Bourg. "Diversity, Social Justice, and the Future of Libraries." Portal: Libraries and the Academy 14, no. 3 (2014): 439-51.

Sandler, Rivanne. "Iranian Studies at the University of Toronto." Iranian Studies 42, no. 4 (2009): 611-20.

Sipanta, Sasan. Chashm'andaz-i musiqi-i Iran [An Overview of Iran's Music]. [Tihran?]: Mu'assasah-i Intisharat-i Mash'al, 1990.

Thacker, Mara. "Beyond the Library of Congress: Collecting Practices of South Asia Area Specialist Librarians." Library Resources \& Technical Services 59, no. 2 (2015): 72-83. https://journals.ala.org/index.php/Irts/article/view/5680/7050.

Tirgan. "Tirgan." Accessed December 9, 2016. http://www.tirgan.ca.

University of Toronto Faculty of Music. "Music Strategic Academic Plan 2016-2021." Unpublished report (2016).

- - . "Ethnomusicology." Accessed December 10, 2016. http://individual.utoronto.ca/kippen/Ethnomusicology/aboutus.html.

Witt, Steve. "International \& Area Studies Collections in 21st Century Libraries: Report of a Conference." International Leads 27, no. 1 (2013): 7-8.

http://www.ala.org/irrt/sites/ala.org.irrt/files/content/intlleads/leadsarchive/201303.pdf. 


\section{Appendix A: Publishers and vendors visited during fieldwork}

\begin{tabular}{|c|c|c|}
\hline $\begin{array}{c}\text { Name of } \\
\text { organization }\end{array}$ & Description & Notes \\
\hline $\begin{array}{l}\text { Mahoor } \\
\text { Institute of } \\
\text { Culture and Art }\end{array}$ & $\begin{array}{l}\text { By far the largest and most important } \\
\text { publisher of music monographs and scores, } \\
\text { and responsible for the only peer-reviewed } \\
\text { scholarly journal of music in Iran. Mahoor is } \\
\text { also a producer of audiovisual materials } \\
\text { with a focus on the classical, folk, and } \\
\text { religious music of Iran. Website: } \\
\text { http://www.mahoor.com }\end{array}$ & $\begin{array}{l}\text { Mahoor Institute's website is } \\
\text { bilingual (Persian and English) and } \\
\text { can be a useful tool for selection } \\
\text { and cataloguing purposes. }\end{array}$ \\
\hline Avaye Sheyda & $\begin{array}{l}\text { Producer of audiovisual materials, as well as } \\
\text { a music journal (ceased), featuring the work } \\
\text { of the late master of Tar, Mohammad Reza } \\
\text { Lotfi. Website: } \\
\text { http://maktabkhanemirza.ir }\end{array}$ & $\begin{array}{l}\text { The publication and production } \\
\text { arms of the Institute do not seem } \\
\text { active since the passing of Mr. Lotfi } \\
\text { in } 2014 \text {. The website is in Persian } \\
\text { only and includes a list of their } \\
\text { productions. }\end{array}$ \\
\hline Part Publications & 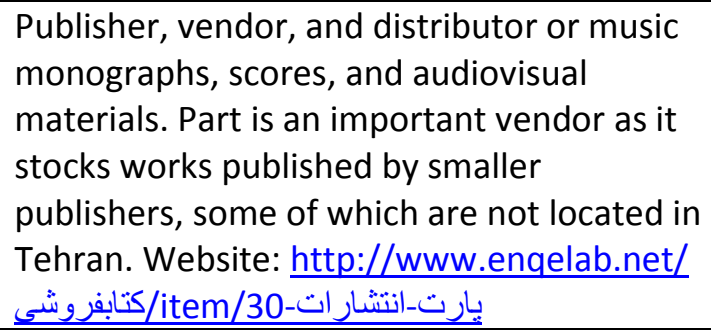 & $\begin{array}{l}\text { Part's website is in Persian only and } \\
\text { rather difficult to navigate. }\end{array}$ \\
\hline Barbad Music & $\begin{array}{l}\text { Producer, vendor, and distributor of } \\
\text { audiovisual materials. Website: } \\
\text { http://www.barbadmusic.com }\end{array}$ & $\begin{array}{l}\text { The website, in Persian only, } \\
\text { provides an excellent catalogue of } \\
\text { Barbad Music's CDs (with audio } \\
\text { samples). Selectors wishing to use } \\
\text { this online catalogue must be } \\
\text { mindful that recordings from other } \\
\text { labels are featured as well, } \\
\text { including productions of the } \\
\text { Mahoor Institute. Therefore, } \\
\text { vetting is required to avoid } \\
\text { potential duplications with other } \\
\text { acquisition plans. }\end{array}$ \\
\hline Hermes Records & $\begin{array}{l}\text { Producer of sound recordings in a variety of } \\
\text { genres including Iranian classical music. } \\
\text { Website: } \\
\text { http://www.hermesrecords.com/en/ }\end{array}$ & $\begin{array}{l}\text { Hermes' website is bilingual } \\
\text { (Persian and English), and includes } \\
\text { a catalogue of their releases } \\
\text { accompanied by audio samples. }\end{array}$ \\
\hline B.A.C.H. & Vendor of various music materials & $\begin{array}{l}\text { Worth a visit due to inclusion of } \\
\text { materials from smaller publishers. }\end{array}$ \\
\hline Chang & Publisher and vendor of music scores & $\begin{array}{l}\text { Mainly important for etudes, } \\
\text { arrangements, and educational } \\
\text { guides. }\end{array}$ \\
\hline
\end{tabular}

